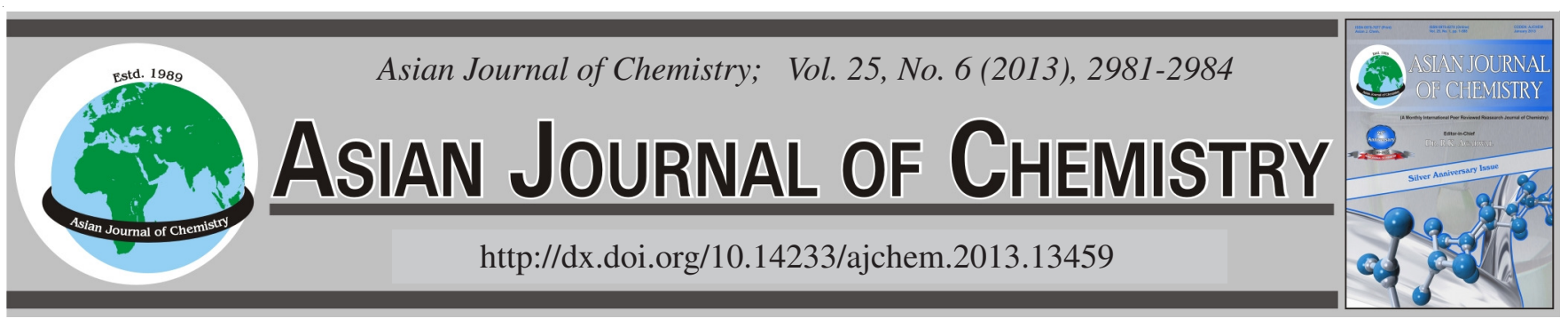

\title{
Spectrophotometric Determination of Nebivolol Hydrochloride in Bulk and Pharmaceutical Formulations
}

\author{
D. Murali ${ }^{1}$, T. Neeharika ${ }^{2}$ and C. Rambabu ${ }^{1, *}$
}

${ }^{1}$ Department of Chemistry, Acharya Nagarjuna University, Dr. M.R. Appa Rao Campus, Nuzvid-521 201, India ${ }^{2}$ GIET School of Pharmacy, NH 16, Chaitanya Knowledge City, Rajahmundry-533 296 , India

*Corresponding author: E-mail: rbchintala@gmail.com

(Received: 16 January 2012;

Accepted: 5 December 2012)

AJC-12501

Two simple, rapid, sensitive and accurate spectrophotometric methods have been developed and validated for the assay of nebivolol
hydrochloride in pure and pharmaceutical formulations. These methods (A and B) were based on nucleophilic substitution and
co-ordination complex formation of nebivolol hydrochloride by 1,2-naphtha quinone-4-sulphonate in alkaline media and cobalt thiocyanate
with the maximum absorption at 460 and $630 \mathrm{~nm}$ respectively. Reaction conditions were optimized to obtain the maximum colour
intensity. Absorbance was found to increase linearly with increase in concentration of nebivolol hydrochloride, which was corroborated
by the correlation coefficient values 0.9986 and 0.9984 respectively. The developed methods were validated with respect to linearity, |
accuracy (recovery), precision, Sandell's sensitivity, molar extinction coefficient and specificity. The system obeyed Beer's law in the
range of $10-60 \mu \mathrm{g} / \mathrm{mL}$ and $8-20 \mu \mathrm{g} / \mathrm{mL}$ for nebivolol hydrochloride. Various analytical parameters have been evaluated and the results
have been validated by statistical methods.
Key Words: Nebivolol hydrochloride, 1,2-Naphtha quinone-4-sulphonate, Cobalt thiocyanate.

\section{INTRODUCTION}

Nebivolol hydrochloride, chemically 1-(6-fluoro chroman2-yl)-2-([2-(6-fluoro chroman-2-yl)-2-hydroxyl ethyl)] amino) ethanol $]^{1,2}$. It is a highly cardio selective vasodilatory $\beta_{1}$ receptor blocker used in treatment of hypertension ${ }^{3}$. The literature survey reveals that several methods are reported for the determination of nebivolol hydrochloride by UV spectrophotometry ${ }^{3-5}$, RP-HPLC ${ }^{6-9}$, RP-LC $^{10}$ and extractive spectrophotometric methods ${ }^{11,12}$.

In this paper, we reported two simple and sensitive visible spectrophotometric methods for the assay of nebivolol hydrochloride. These methods are based on nucleophilic substitution and coordination complex formation of drug with reagents such as 1,2-naphtha quinone-4-sulphonate and cobalt thiocyanate giving coloured products.

\section{EXPERIMENTAL}

An ELICO, UV-visible digital spectrophotometer with $1 \mathrm{~cm}$ matched quartz cells were used for all spectral and absorbance measurements. An ELICO LI- 120 digital $\mathrm{pH}$ meter was used for all $\mathrm{pH}$ measurements. Pure drug was procured from Hetero Drugs Ltd., Hyderabad as a gift sample. The reagents namely 1,2-naphtha quinone-4-sulphonate, cobalt thiocyanate, $\mathrm{NaOH}$ (AR Grade) supplied by SD Fine Chemicals Ltd., Mumbai are used without any further purification. Nitrobenzene was (AR Grade) supplied by SD Fine Chemicals Ltd., Mumbai is used throughout the work.

Standard drug preparation: The working standard solution $(1.0 \mathrm{mg} / \mathrm{mL})$ of nebivolol hydrochloride was prepared by dissolving $100 \mathrm{mg}$ of the drug in $100 \mathrm{~mL}$ of distilled water. This stock solution was further diluted with the same solvent to get $200 \mu \mathrm{g} / \mathrm{mL}$ of working standards for both methods respectively.

Pharmaceutical formulations: An accurately weighed portion of tablet content equivalent to about $300 \mathrm{mg}$ of nebivolol hydrochloride was transferred into a $100 \mathrm{~mL}$ volumetric flask. About $100 \mathrm{~mL}$ of warm isopropyl alcohol were added and shaken well and mixed thoroughly for about $20 \mathrm{~min}$. The solution was filtered. The filtrate was evaporated to dryness. The residue was appropriately diluted for the preparation of formulation solutions for different methods as given under standard solution preparations to fit into the calibration graph.

Preparation of calibration curve: Calibration curves were constructed in accordance with the optimum conditions.

Method-A: Aliquot of standard nebivolol hydrochloride solution, $0.5-3.0 \mathrm{~mL}(200 \mu \mathrm{g} / \mathrm{mL})$ were transferred into a series 
of calibrated tubes containing $0.2 \mathrm{~mL}$ of $0.1 \mathrm{~N} \mathrm{NaOH}$ and $0.2 \mathrm{~mL}$ of $0.5 \%$ 1,2-naphtha quinone-4-sulphonate reagent solution was added in each tube and the contents were heated at $50{ }^{\circ} \mathrm{C}$ for $5 \mathrm{~min}$ and cooled. This operation was performed in the dark. Then $0.5 \mathrm{~mL}$ of conc. $\mathrm{H}_{2} \mathrm{SO}_{4}$ was added slowly, mixed and the absorbance (Fig. 1) was measured after 5 min at $\lambda_{\max } 460 \mathrm{~nm}$ against a reagent blank prepared similarly. The amount of nebivolol hydrochloride was calculated from its calibration curve (Fig. 2).

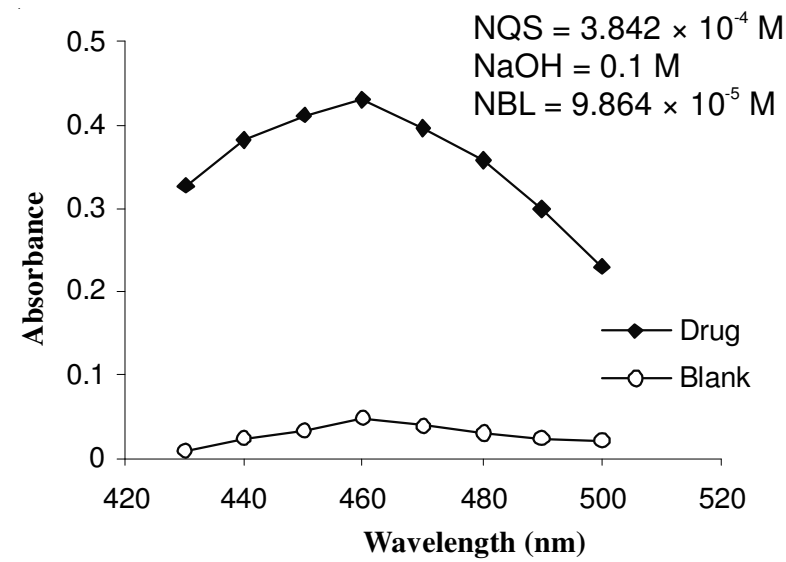

Fig. 1. Absorption spectrum of nebivolol hydrochloride (NBL) with 1,2naphtha quinone-4-sulphonate (NQS) (Method A)

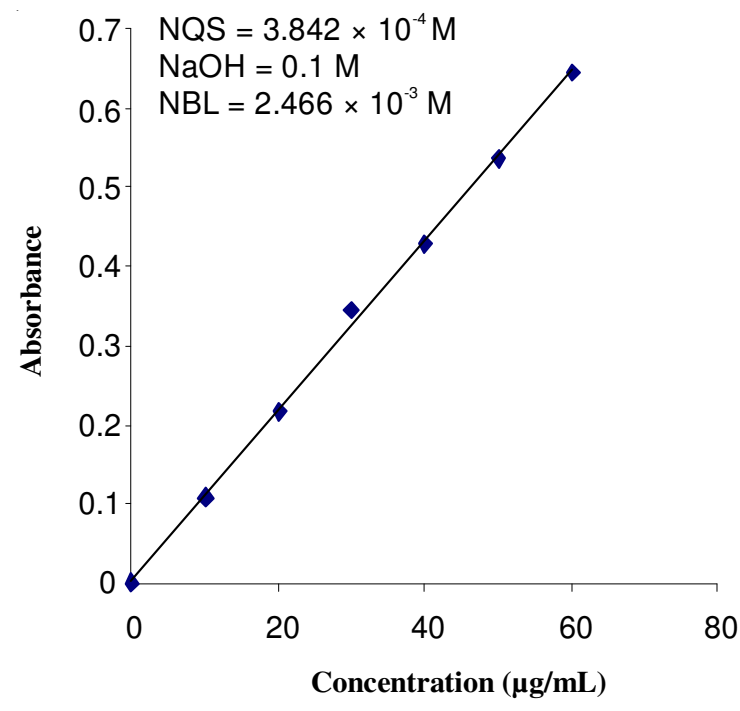

Fig. 2. Beer's law plot of nebivolol hydrochloride (NBL) with 1,2-naphtha quinone-4-sulphonate (NQS) (Method A)

Method-B: Aliquots of standard nebivolol hydrochloride solution, $2.0-5.0 \mathrm{~mL}(200 \mu \mathrm{g} / \mathrm{mL})$ were delivered into a series of calibrated tubes. $2.0 \mathrm{~mL}$ of buffer of $\mathrm{pH} 2.0$ and $5 \mathrm{~mL}$ of cobalt thiocyanate solutions were added and the total volume in each tube was adjusted to $15 \mathrm{~mL}$ with distilled water. These solutions in the tubes were transferred to $125 \mathrm{~mL}$ separating funnel. To each separating funnel $10.0 \mathrm{~mL}$ of nitrobenzene was added and the contents were shaken for $2 \mathrm{~min}$. The two phases were allowed to separate and the absorbance of the separated nitrobenzene layer was measured after $20 \mathrm{~min}$ absorbance (Fig. 3) was measured at $\lambda_{\max } 630 \mathrm{~nm}$ against a similar reagent blank. The amount of nebivolol hydrochloride was deduced from its calibration curve (Fig. 4).

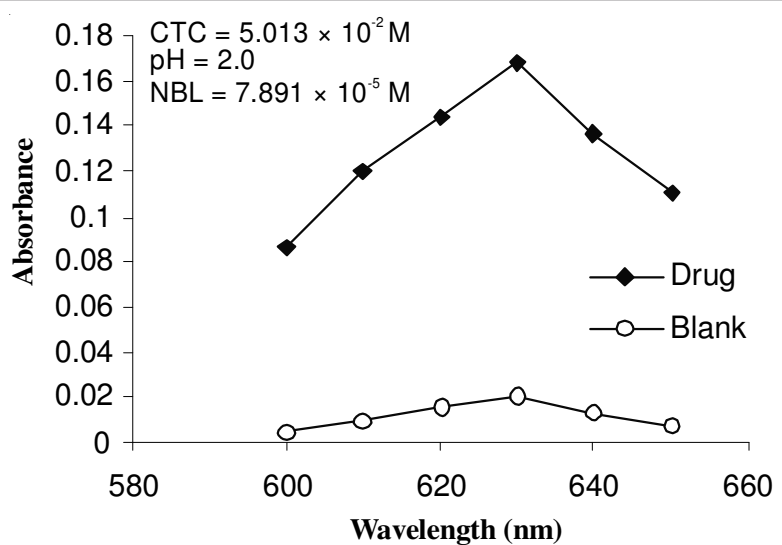

Fig. 3. Absorption spectrum of nebivolol hydrochloride (NBL) with cobalt thiocyanate (CTC) (Method B)

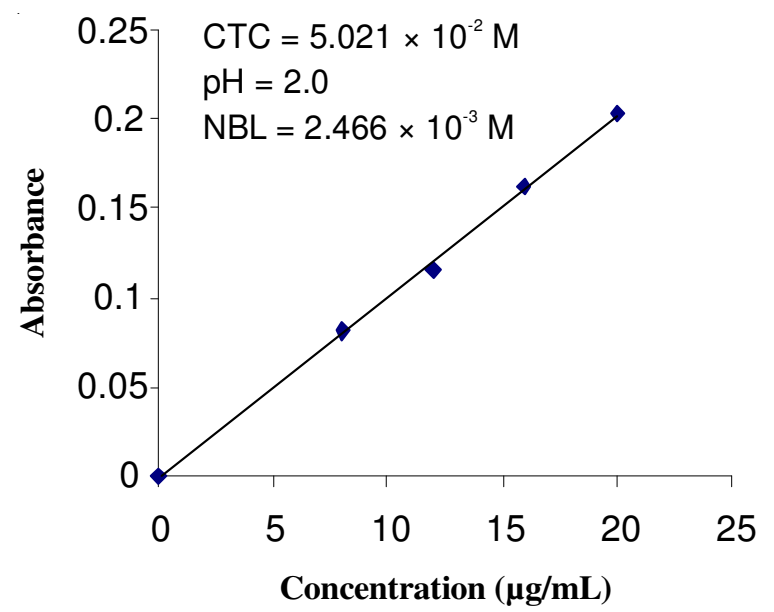

Fig. 4. Beer's law plot of nebivolol hydrochloride (NBL) with cobalt thiocyanate (Method B)

The calibration graphs (Figs. 2 and 4 ) are the linear over the concentration ranges are within permissible range. The optical characteristics and statistical data for the regression equation of the proposed methods are presented in (Table-1). The amount of nebivolol hydrochloride was calculated from the corresponding Beer-Lambert's plot.

TABLE-1

OPTICAL CHARACTERISTICS, PRECISION AND ACCURACY OF THE PROPOSED METHODS FOR NEBIVOLOL HYDROCHLORIDE

\begin{tabular}{lcc}
\hline Parameters & Method A & Method B \\
\hline$\lambda_{\text {max }}(\mathrm{nm})$ & 460 & 630 \\
Beer's law limits $(\mu \mathrm{g} / \mathrm{mL})$ & $10-60$ & $8-20$ \\
Molar absorptivity $\left(\mathrm{L} \mathrm{mol}{ }^{-1} \mathrm{~cm}^{1}\right)$ & $0.9904 \times 10^{3}$ & $2.076 \times 10^{3}$ \\
Sandell's sensitivity $\left(\mu \mathrm{g} / \mathrm{cm}^{2} / 0.001\right.$ & $9.302 \times 10^{-2}$ & $3.940 \times 10^{-2}$ \\
absorbance unit) & & \\
Optimum photometric range $(\mu \mathrm{g} / \mathrm{mL})$ & $12.5-50$ & $10-18$ \\
Regression equation $(\mathrm{Y}=\mathrm{a}+\mathrm{bc}) *$ : & & \\
Slope $(\mathrm{b})$ & 0.0108 & 0.0008 \\
Intercept (a) & 0.0023 & 0.0101 \\
Correlation coefficient $(\mathrm{r})$ & 0.9986 & 0.9984 \\
Relative standard deviation** $(\%)$ & 0.3612 & 0.5264 \\
Range of error (confidence limits)** $(\%)$ & & \\
0.05 level & 0.1404 & 0.0440 \\
0.01 level & 0.2078 & 0.0652 \\
\hline
\end{tabular}

$* \mathrm{Y}=\mathrm{a}+\mathrm{bx}$, where ' $\mathrm{Y}$ ' is the absorbance and $\mathrm{x}$ is the concentration of Nebivolol $\mathrm{HCl}$ in $\mu \mathrm{g} / \mathrm{mL}$; **For eight replicates 
Optimization of reaction conditions: The reactions were investigated on effect of the reaction time, the reaction temperature, buffer $\mathrm{pH}$, choice of the organic solvent (nitrobenzene) and ratio of the organic phase to the aqueous phase, volume of $\mathrm{NaOH}$ solution as well as volume of 1,2-naphtha quinone4-sulphonate and cobalt thiocyanate solutions. Control experiments are carried out by measuring absorbance at 460 and $630 \mathrm{~nm}$ of series of the solutions varying one and fixing the other parameter for method A and B, respectively.

\section{RESULTS AND DISCUSSION}

Nebivolol hydrochloride is involved in nucleophilic substitution reaction in basic medium with 1,2-naphtha quinone-4-sulphonate and $\mathrm{NaOH}$ as well as co-ordination complex formation with cobalt thiocyanate, which is extracted into nitrobenzene solvent were quantitatively measured.

Optical characteristics: The optical characteristics such as Beer's law limits, Sandell's sensitivity, molar extinction coefficient, per cent relative standard deviation, per cent range of error ( 0.05 and 0.01 confidence limits) were calculated for all the methods and results are summarized in Table-1.The values obtained for the determination of nebivolol hydrochloride in pharmaceutical formulations (tablets) by the proposed methods are presented in Table-2. Studies reveal that the common excipients and other additives usually present in the tablets did not interfere in the proposed methods.

\begin{tabular}{cc|cc|cc}
\multicolumn{6}{c}{ TABLE-2 } \\
\multicolumn{5}{c}{$\begin{array}{c}\text { DETERMINATION OF NEBIVOLOL HCl IN } \\
\text { PHARMACEUTICAL FORMULATIONS }\end{array}$} \\
\hline $\begin{array}{c}\text { Formul- } \\
\text { ations }\end{array}$ & $\begin{array}{c}\text { Labelled } \\
\text { amount } \\
(\mathrm{mg} / \mathrm{mL})\end{array}$ & \multicolumn{2}{|c}{$\begin{array}{c}\text { Amount found* by } \\
\text { proposed methods }\end{array}$} & $\begin{array}{c}\text { Recovery** by proposed } \\
\text { methods }(\%)\end{array}$ \\
\cline { 2 - 6 } & Method-A & Method-B & Method-A & Method-B \\
\hline Tablet & 5 & 4.95 & 4.96 & 99.4 & 99.8 \\
Tablet & 10 & 9.96 & 9.95 & 99.7 & 99.3 \\
\hline
\end{tabular}

*Average of 8 determinations; **Recovery of amount added to the pharmaceutical formulation (Average of three determinations)

Precision and accuracy: The precision of each methods was ascertained from the absorbance values obtained by the actual determination of 8 replicates of a fixed amount of nebivolol hydrochloride in total solution. The per cent relative standard deviation and percent range error (at 0.05 and 0.01 confidence limits) were calculated for the proposed methods and results are summarized in Table- 1 . To determine the accuracy of each proposed method, different amounts of bulk samples of nebivolol hydrochloride within the Beer's law limits were taken any analyzed by the proposed method. The results (per cent recovery) were recorded in Table-2.

\section{Scheme of the coloured products}

Method-A: In this method, the secondary amino group of nebivolol hydrochloride permits the colour development with the 1,2-naphtha quinone-4-sulphonate through the nucleophilic substitution reaction. The coloured species is represented as given in the Scheme-I.

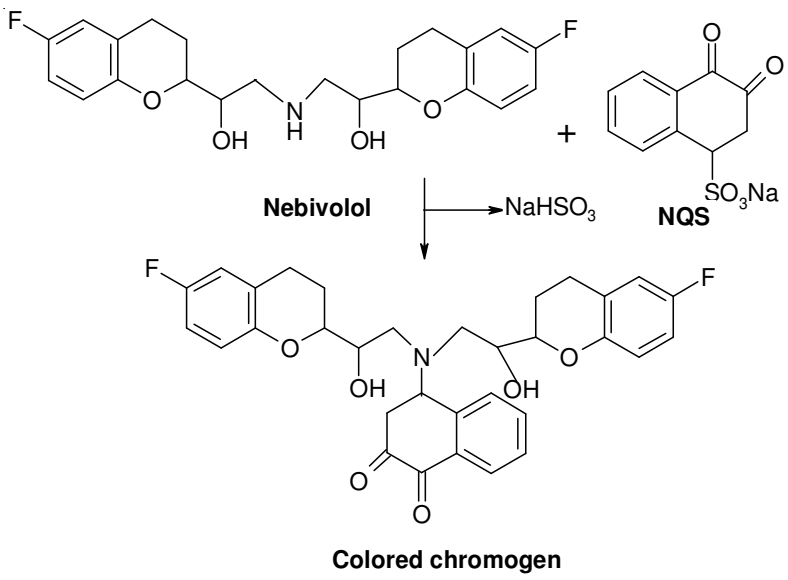

Scheme-I: Nucleophilic substitution reaction of nebivolol hydrochloride with 1,2-naphtha quinone-4-sulphonate (NQS)

Method-B: In this method the coloured species formed is the coordination complex of drug (electron donor) and the central atom of cobalt thiocyanate, which is extractable into nitrobenzene from aqueous solution. Formation of the coloured complex when nebivolol hydrochloride was treated with cobalt thiocyanate due to the presence of secondary amine group is basis in the present investigation. Scheme-II represents the formation of coloured species in the method.

\section{Conclusion}

The proposed methods are simple, selective and reproducible and can be used in the routine analysis of nebivolol hydrochloride in bulk drug and formulations with reasonable accuracy and precision.

\section{ACKNOWLEDGEMENTS}

The authors thank the authorities of university for providing the research facilities to carry out the present work and greatly acknowledged to M/s Hetero Drugs Ltd., Hyderabad, India for providing a gift sample of the drug.<smiles>CNCC(O)C1CCc2cc(F)ccc2O1</smiles><smiles>CC(O)C1CCc2cc(F)ccc2O1</smiles>

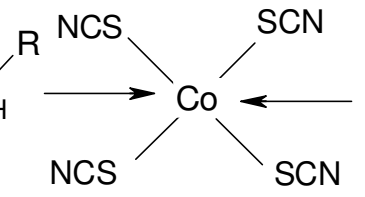<smiles>[R]NCC(O)C1CCc2cc(F)ccc2O1</smiles>

Colored complex 


\section{REFERENCES}

1. K. Bylund, Nebivolol, xPharm: The Comprehensive Pharmacology Reference, pp. 1-5 (2007).

2. Martindale-The Complete Drug Reference, edn. 34 ${ }^{\text {th }}$, pp. 938-39 (2005)

3. M.M. Kamila, N. Mondal, L.K. Ghosh and B.K. Gupta, A. DiePharmazie, 62, 486 (2007).

4. A.L. Rao, K.R. Rajeswari and G.G. Sankar, E.- J. Chem., 7, 445 (2010)

5. B. Dhandapani, N.T. Moorthy and D.J. Prakesh, E.-J. Chem., 7, 341 (2010).

6. K.R. Rajeswari, G.G. Sankar, A.L. Rao, D.B. Raju and J.V.L.N Seshagiri Rao, Asian J. Chem., 17, 1259 (2005).
7. Y. Gupta, A. Shrivastava, D. Duggal, A. Patel and S. Aarwal, J. Young Pharmacist, 1, 264 (2009).

8. S.V. Kokil and M.S. Bhatia, Indian J. Pharm. Sci., 71, 111 (2009)

9. L.J. Patel, B.N. Suhasia and P.B. Shah, Indian J. Pharm. Sci., 69, 594 (2007).

10. J.S. Joshi, A. Pradnya, Karbhari and Suvarna, Bhoir, Chromatographia, 70, 557 (2011).

11. D.G.T. Parambi, M. Mathew, A. Jose and K.G. Revikumar, Indian J. Pharm. Sci., 23, 3 (2010).

12. D. Murali, S.V. Venkata Rao, N.V.N. Malleswara Rao and C. Rambabu, J. Pharm. Res., 4, 4455 (2011). 